\title{
Role of Galactography in the Early Diagnosis of Breast Cancer
}

\author{
Juan D. Berná-Serna ${ }^{a} \quad$ Carolina Torres-Ales $^{a} \quad$ Juan D. Berná-Mestre ${ }^{a} \quad$ Luis Polo $^{b}$ \\ aDepartment of Radiology, \\ ${ }^{\mathrm{b}}$ Department of Pathology, Virgen de la Arrixaca University Hospital, El Palmar (Murcia), Spain
}

\section{Keywords}

Galactography · Galactogram Imaging Classification

System · GICS · Pathologic nipple discharge .

Histopathologic diagnosis

\section{Summary}

Background: The purpose of this study was to evaluate the usefulness of galactography (GL) in the early diagnosis of breast cancer in patients with pathologic nipple discharge (PND). Patients and Methods: We retrospectively studied all galactograms obtained in 117 women with PND, who subsequently had a biopsy. The findings detected in the galactograms of the patients in this study were assigned to different categories of the Galactogram Image Classification System (GICS): GICS 2, benign; GICS 3, probably benign; GICS 4, suspicious for malignancy; and GICS 5, highly suspicious for malignancy. Results: The galactograms were classified into GICS 2 (29 cases; $24.7 \%$ ), GICS 3 (42 cases; $35.8 \%$ ), GICS 4 (30 cases; $25.6 \%$ ), and GICS 5 (16 cases; 13.6\%). A good correlation was observed between histological diagnosis and GICS categories $(p<0.05)$. All cases diagnosed with carcinoma ( $n=18$ ) were classified in GICS categories 4-5: ductal carcinoma in situ in 14 cases $(11.9 \%)$ and invasive carcinoma in 4 cases (3.4\%). Conclusion: $\mathrm{GL}$ is a useful procedure in the early diagnosis of breast cancer in patients with PND.

\section{Introduction}

Nipple discharge is a common symptom seen in breast cancer clinics, with reported frequencies between 3 and $8 \%[1,2]$. Galactography (GL), or ductography, is the gold standard in patients with pathological nipple discharge (PND) which is

\section{Schlüsselwörter \\ Galaktographie · Galactogram Imaging Classification System · GICS · Pathologische Mamillensekretion . Histopathologische Diagnose}

\section{Zusammenfassung}

Hintergrund: Ziel dieser Studie war es, den Nutzen der Galaktographie (GL) zur Frühdiagnose von Mammakarzinomen bei Patientinnen mit pathologischer Mamillensekretion zu beurteilen. Patientinnen und Methoden: Die Galaktogramme von 117 Frauen mit pathologischer Mamillensekretion, bei denen eine Biopsie durchgeführt wurde, wurden retrospektiv geprüft. Die aus den Galaktogrammen hervorgehenden Befunde wurden verschiedenen GICS (Galactogram Image Classification System)Kategorien zugeteilt: GICS 2, gutartig; GICS 3, wahrscheinlich gutartig; GICS 4, Tumorverdacht und GICS 5, starker Tumorverdacht. Ergebnisse: Die Galaktogramme wurden wie folgt klassifiziert: GICS 2 (29 Fälle; 24,7\%), GICS 3 (42 Fälle; 35,8\%), GICS 4 (30 Fälle; 25,6\%) und GICS 5 (16 Fälle; 13,6\%). Zwischen der histologischen Diagnose und den GICS-Kategorien bestand eine starke Korrelation $(p<0,05)$. Alle Patientinnen, bei denen ein Karzinom diagnostiziert wurde ( $n=18)$, waren als GICSKategorie 4-5 klassifiziert worden: duktales Karzinom in 14 Fällen $(11,9 \%)$ und invasives Karzinom in 4 Fällen $(3,4 \%)$. Schlussfolgerung: Die GL ist bei der Frühdiagnose von Mammakarzinomen bei Patientinnen mit pathologischer Mamillensekretion von Nutzen.

usually defined as a non-lactational, persistent, spontaneous, single-orifice nipple discharge, either bloody, serous, or clear [3-8]. Papilloma has been reported as one of the most common causes of such discharge, and 5-20\% of cases are associated with malignancy [3, 7-9]. GL is a fundamental procedure for detecting and locating intraductal lesions [3, 6, 10-14].

\section{KARGER}

Fax +497614520714

Information@Karger.com

www.karger.com (c) 2013 S. Karger GmbH, Freiburg

$1661-3791 / 13 / 0082-0122 \$ 38.00 / 0$

Accessible online at:

www.karger.com/brc
Dr. Juan D. Berná-Serna

Department of Radiology

Virgen de la Arrixaca University Hospital

30120 El Palmar (Murcia), Spain

jdberna@gmail.com 
However, the use of GL is still a subject of controversy [1517]. Several studies have reported that GL does not enable benign lesions to be differentiated from malignant lesions $[3,6,7]$. However, other studies describe galactographic findings suggestive of malignant lesions $[8,18,19]$. A classification system for findings observed in galactograms was reported recently: the Galactogram Image Classification System (GICS) which shows a good correlation between GICS categories and histological diagnosis [20]. The aim of this study was to investigate the usefulness of GL in the early diagnosis of breast cancer in patients with PND.

\section{Patients and Methods}

Between January 2000 and November 2011, we performed a retrospective study of 117 patients (mean age: $51.3 \pm 23.5$ years; age range: $25-78$ years) who were evaluated with GL and underwent excisional biopsy. The study was approved by the Institutional Review Board. Informed consent was not required. GL was done using the coaxial technique [4], and was performed by the same radiologist (J.B.S) with more than 25 years' experience in GL. With this technique, the discharging duct is cannulated with a standard straight guidewire (18 gauge $(0.018$ inches, $0.46 \mathrm{~mm}), 50 \mathrm{~cm}$ long) with a 3 -cm flexible tip (Cook, Bjaerskov, Denmark). A 24-gauge, 19-mm long Abbocath Catheter (Abbot, Sligo, Ireland) is introduced over the guidewire into the duct. When the Abbocath is in place, the guidewire is removed, a syringe is connected, and a small volume of contrast material is slowly injected. The studies were performed on digital (Lorad Selenia, Hologic Inc., Bedford, MA, USA) or analog (Mammomat 2, Siemens AG, Erlangen, Germany) mammography systems. Craniocaudal and mediolateral mammograms were obtained after contrast medium injection. All galactograms were reviewed consensually by 2 radiologists with experience in breast imaging. The location of the abnormalities detected in the galactograms was determined as retro-periareolar, central, or peripheral. The findings detected in the galactograms of the 117 patients in this study were categorized according to the GICS system: GICS 1, galactogram which is normal or negative for malignancy; a ductal system with harmonious ramification is seen, although ductal systems are highly variable with regard to length, ramifications, and distribution; a uniform arborization must be observed, with smooth duct contours and a caliber that decreases progressively from the main duct $(\leq 3 \mathrm{~mm})$ to the terminal ramification. GICS 2 , benign finding; this category includes ductal ectasia - an increase is noted in the caliber of the ductal system (> $3 \mathrm{~mm}$ ) without ductal filling defects to suspect intraductal lesions which must be differentiated from artifacts or pseudolesions that may occasionally be visualized; fibrocystic changes - a normal ductal system is visualized with contrast material communication between ducts and cysts. GICS 3, probable benign finding; a macrodefect in ductal filling with ductal ectasia is observed which usually expands the affected duct (spaceoccupying lesion) or causes complete obstruction of the duct with concave termination; the most common location is in the main duct or in a bifurcation with a segmental duct. GICS 4, suspicious abnormality; multiple macrodefects in filling with ductal ectasia are observed, and the most common location is in segmental and subsegmental ducts. GICS 5, high suspicion of malignancy; this category includes the following abnormalities: multiple microdefects with a moth-eaten appearance and ductal wall irregularities; complete obstruction of the duct with abrupt or irregular termination; periductal extravasation of contrast material in women aged over 50 years; stenosis (single or multiple) with an abrupt change in ductal caliber; areas of duct narrowing and sacculation located in segmental ducts, subsegmental ducts, or ramifications; marked density on the galactogram in the corresponding area of ductal distortion; and microcysts are visualized with filling defects. The radiologists were unaware of each patient's histopathologic diagnosis. Radiographically guided preoperative wire location was performed in 82 cases $(70 \%)$ and sonography in the remaining 35 cases $(30 \%)$.

We reviewed the medical records of all the patients and recorded the following parameters: age, physical findings, type of nipple discharge, mammograms, and histopathological findings. The mammograms were evaluated using the criteria given by the American College of Radiology Breast Imaging Reporting and Data System (BI-RADS) [21]. The cases classified as BI-RADS 1 and BI-RADS 2 were considered normal mammography examinations. Data on histopathologic findings were reviewed by 2 pathologists with experience in breast pathology, and the lesions were classified into the following categories: i) duct ectasia; ii) fibrocystic changes; iii) usual ductal hyperplasia; iv) atypical ductal hyperplasia; v) solitary intraductal papillomas; vi) papillomatosis; vii) ductal carcinoma in situ (DCIS); and viii) invasive ductal carcinoma. Tumors were graded based on the American Joint Committee on Cancer classification, where Tis $=$ carcinoma in situ, T1a $=$ tumor $>0.1 \mathrm{~cm}$ but $\leq 0.5 \mathrm{~cm}$ in its greatest dimension.

Statistical analysis was performed using the SPSS statistical software package version 15 (SPSS Inc., Chicago, IL, USA). A descriptive statisti$\mathrm{cal}$ analysis of each variable was conducted giving the frequency of distribution. The usual parameters were also calculated for the quantitative variables: mean, standard deviation, maximum and minimum. The relationship between qualitative variables was determined by analysis of contingency tables using the Pearson's chi-square test, and the quantitative variables were analyzed by Student's t test. ANOVA was used to compare groups. A p $<0.05$ was considered statistically significant.

\section{Results}

The physical breast examination was normal in all 117 cases. Nipple discharge was bloody $(n=67)$, serous $(n=34)$, serosanguineous $(n=12)$, or clear $(n=4)$. Mammography was normal in 110 patients (94\%), BI-RADS 3 density asymmetry was seen in 3 cases $(2.5 \%)$, and BI-RADS 3 microcalcifications in 4 cases $(3.4 \%)$.

The findings observed in the galactograms using the GICS categories included: GICS 2 in 29 cases (24.7\%); GICS 3

Table 1. Correlation of 117 galactographic abnormalities (GICS 2, 3, 4, 5) with their location in the breast

\begin{tabular}{|c|c|c|c|c|c|c|c|}
\hline GICS category & $\begin{array}{l}\text { Retro- } \\
\text { periareolar }\end{array}$ & Central & Peripheral & $\begin{array}{l}\text { Central- } \\
\text { peripheral }\end{array}$ & $\begin{array}{l}\text { Retro- } \\
\text { peripheral }\end{array}$ & $\begin{array}{l}\text { Retro- } \\
\text { central }\end{array}$ & Total \\
\hline 2 & 12 & 5 & 3 & 4 & 2 & 3 & 29 \\
\hline 3 & 10 & 8 & 3 & 5 & 7 & 9 & 42 \\
\hline 4 & 2 & 4 & 5 & 11 & 5 & 3 & 30 \\
\hline 5 & 2 & 2 & 3 & 3 & 2 & 4 & 16 \\
\hline Total & 26 & 19 & 14 & 23 & 16 & 19 & 117 \\
\hline
\end{tabular}


Table 2. Correlation of GICS categories with the histological diagnosis

\begin{tabular}{|c|c|c|c|c|c|c|c|c|c|}
\hline GICS category & Ductal ectasia & FCs & $\begin{array}{l}\text { Solitary } \\
\text { papilloma }\end{array}$ & Papillomatosis & $\mathrm{UDH}$ & $\mathrm{ADH}$ & $\begin{array}{l}\text { Invasive } \\
\text { carcinoma }\end{array}$ & DCIS & Total \\
\hline 2 & 12 & 15 & 2 & 0 & 0 & 0 & 0 & 0 & 29 \\
\hline 3 & 0 & 0 & 37 & 0 & 3 & 2 & 0 & 0 & 42 \\
\hline 4 & 2 & 1 & 0 & 21 & 1 & 3 & 0 & 2 & 30 \\
\hline 5 & 0 & 0 & 0 & 0 & 0 & 0 & 5 & 11 & 16 \\
\hline Total & 14 & 16 & 39 & 21 & 4 & 5 & 5 & 13 & 117 \\
\hline
\end{tabular}

FCs = Fibrocystic changes; UDH = usual ductal hyperplasia; ADH = atypical ductal hyperplasia; DCIS = ductal carcinoma in situ.

in 42 cases $(35.8 \%)$, GICS 4 in 30 cases $(25.6 \%)$, and GICS 5 in 16 cases $(13.6 \%)$. The location of the ductal lesions and their correlation with the GICS categories are summarized in table 1 . Most of the abnormalities corresponding to GICS 3 were located in the retro-periareolar region, whereas the GICS 4 and GICS 5 anomalies were preferentially located in the central and peripheral areas, with statistically significant differences $(\mathrm{p}<0.05)$.

The histopathologic findings in the 117 breast surgical biopsies included: duct ectasia in 14 cases (11.9\%), fibrocystic changes in 16 cases $(13.6 \%)$, solitary papilloma in 39 cases $(33.3 \%)$, papillomatosis in 21 cases $(17.9 \%)$, usual ductal hyperplasia in 4 cases $(3.4 \%)$, atypical ductal hyperplasia in 5 cases $(4.2 \%)$, ductal carcinoma in situ in 14 cases $(11.9 \%)$, and invasive carcinoma in 4 cases $(3.4 \%)$. The most common lesion was solitary intraductal papilloma. The age at papilloma presentation averaged $46.7 \pm 10.3$ years (range $25-73$ years); the mean age of the cases of papillomatosis was $51.3 \pm 12.4$ years (range 39-63 years); and the mean age of the patients with carcinoma was $56.2 \pm 23.8$ years (range 36-78 years). Statistically significant differences were found between patients with benign and malignant lesions with regard to age $(p<0.05)$. Also, early diagnosis was observed with only low extension of ductal spread and low T-stage. Therefore, stage of breast cancer was: Tis $(n=14)$, and T1a $(n=4)$.

The correlations between GICS categories and histopathologic findings are shown in table 2 and are statistically significant $(\mathrm{p}<0.05)$. Both the benign and malignant lesions were assigned adequately to the different GICS categories. As for the 7 cases with abnormal mammograms, 3 cases with density asymmetry (BI-RADS 3) had galactograms classified as GICS $4(\mathrm{n}=2)$, and the histological findings were papillomatosis. 2 of the 4 cases with microcalcifications were classified as GICS 4 and histology was atypical ductal hyperplasia $(\mathrm{n}=2)$, and in the remaining 2 cases histology was DCIS corresponding to GICS 5.

\section{Discussion}

Nipple discharge of the female breast is an important clinical problem that causes both discomfort and anxiety to many women. Management of PND without an associated mass and normal mammography remains controversial. GL is recom- mended for the management of PND as it allows identification of ductal anomalies and their location as well as guidance for surgical excision $[3,6,9,10,12,14]$. However, GL is still the subject of debate because establishing a differential diagnosis between benign and malignant lesions is considered difficult. The GICS classification system was reported recently [20], and GL has been described as a useful procedure for differentiating benign from malignant lesions. Furthermore, a recent study [22] reports that direct magnetic resonance imaging galactography may provide more diagnostic information than conventional GL in patients with PND, because it can show both ductal morphology and the extent of disease before surgery. Also, sonography is a valuable method for localizing intraductal abnormalities, especially papillomatous lesions, in patients with nipple discharge with no other clinical or radiologic findings [23]. However, the sonographic detection of DCIS is difficult. Other investigation modalities of PND include exfoliative cytology and mammary (or fiber optic) ductoscopy, although the sensitivity of cytology is low and only positive results have value $[3,13]$, while mammary ductoscopy is an emerging technology that allows direct visualization and biopsy examination of the mammary ductal abnormalities [24, 25].

Several studies [8, 18-20] report galactographic findings suggestive of malignancy, such as ductal stenosis, multiple irregular filling defects, ductal wall irregularity, and ductal distortion. In our study, we observed a very good correlation between GICS category 5 and carcinoma, and the galactographic findings included microdefects with a moth-eaten appearance and ductal wall irregularities (fig. 1) and ductal cut-off (fig. 2).

It is commonly reported that women aged over 50 years with PND tend to have breast cancer more often [10]. This is observed in the present study, although 6 cases of carcinoma were seen in women aged $<50$ years. However, solitary intraductal papilloma usually occurs in younger women $(<50$ years). We consider it extremely important to conduct a thorough analysis of the ductal system to detect subtle ductal lesions that suggest malignancy. It is also essential to locate breast lesions especially for planning surgery. The present study shows that most solitary intraductal papillomas were observed in the retro-periareolar region, whereas the carcinomas were located in the central and/or peripheral areas. Hou et al. [19] reported that most carcinoma patients presenting 


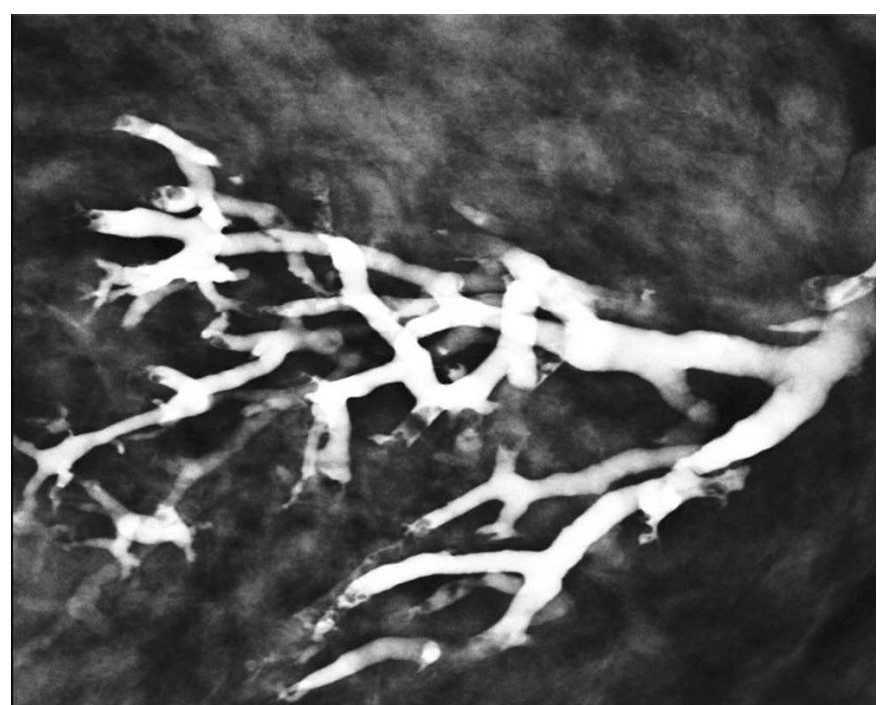

Fig. 1. Image from a 43-year-old woman with pathological nipple discharge classified as GICS 5. Galactogram showing multiple filling microdefects with a moth-eaten appearance and ductal wall irregularities. Histological diagnosis: ductal carcinoma in situ.

with discharge had their lesions located $>2 \mathrm{~cm}$ from the nipple.

The evaluation and diagnosis of PND is important for the early detection of carcinoma. Although nipple discharge is predominantly due to a benign etiology, approximately $6-20 \%$ of cases are due to breast carcinoma $[3,6,9,10]$. The lesions that cause nipple discharge are not usually visible on mammography. In such cases, GL is fundamental for detecting ductal lesions. Physical examination was negative in all the patients in the present study, and mammography was normal in most of the cases. However, carcinoma was diagnosed in $15.3 \%$ of the cases. Only 2 cases of breast cancer diagnosed among the patients with BI-RADS 3 abnormal mammograms had a radiological finding of microcalcifications, and both were classed as GICS 5. We believe therefore that galactography is especially valuable when neither physical examination nor mammography reveal the underlying cause of PND, and that it is an important procedure for early breast cancer detection.

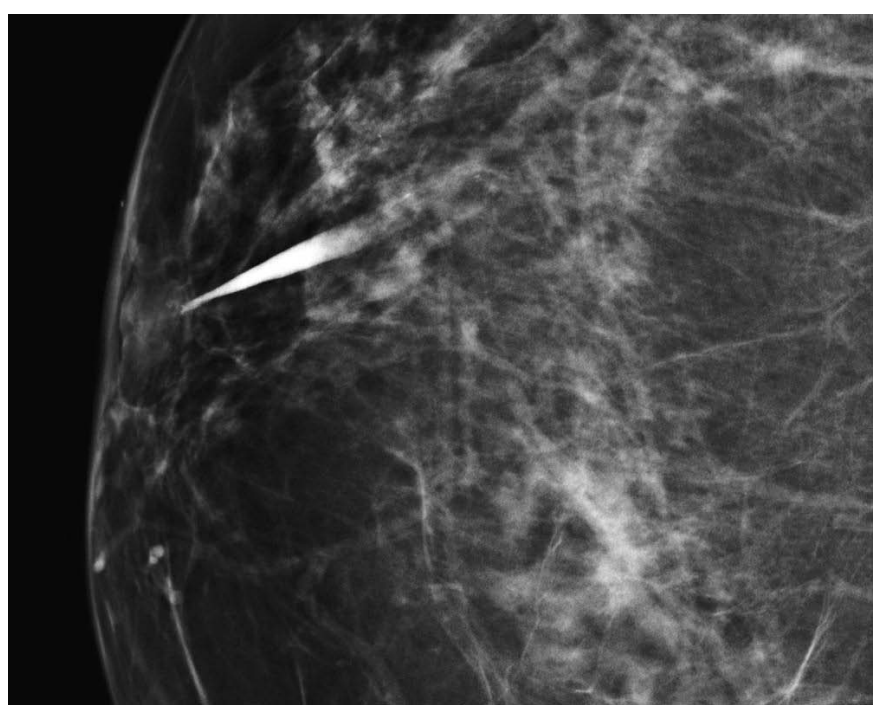

Fig. 2. Image from a 54-year-old woman with pathological nipple discharge classified as GICS 5. Galactogram showing complete obstruction of the duct. Histopathologic diagnosis: invasive carcinoma.
A limitation of the study is the retrospective design for image interpretation. Also, a determination of the sensitivity and specificity of the GICS categories was not performed. These statistical parameters together with the positive predictive value of the GICS categories could well be evaluated in prospective studies. In conclusion, GL helps determine the location of lesions in the ductal system and differentiate benign from malignant lesions. It is a useful tool for the early detection of breast cancer in patients with PND. Moreover, the GICS classification system used in this study shows a good correlation with the histopathologic findings.

\section{Disclosure Statement}

The authors report no conflicts of interest.

\section{References}

1 Gulay H, Bora S, Kilicturgay S, Hamaloglu E, Goskel HA: Management of nipple discharge. J Am Coll Surg 1994;178:471-474.

2 Lamont JP, Dutz RP, Kuhn JA, Grant MD Jones RC: Galactography in patients with nipple discharge. Proc (Bayl Univ Med Cent) 2000;13:214-216.

3 Tabar L, Dean PB, Pentek Z: Galactography: the diagnostic procedure of choice for nipple discharge. Radiology 1983;149:31-38.

4 Berná JD, Guirao J, García V: A coaxial technique for performing galactography. AJR 1989;153:273274.
5 Cardenosa G, Eklund W: Benign papillary neoplasm of the breast: mamographic findings. Radiology 1991:181:751-755.

6 Slawson SH, Johnson BA: Ductography: how to and what if? Radiographics 2001;21:133-150.

7 Funovics MA, Philipp MO, Lackner B, Fuchsjaeger M, Funovics PT, Metz V: Galactography: method of choice in pathologic nipple discharge? Eur Radiol 2003;13:94-99.

$\checkmark$ Cho N, Moon WK, Chung SY, Cha JH, Cho KS, Kim EK, Oh KK: Ductographic findings of breast cancer. Korean J Radiol 2005;6:31-36.
9 Van Zee KJ, Ortega Pérez G, Minnard E, Cohen MA: Preoperative galactography increases the diagnostic yield of major duct excision for nipple discharge. Cancer 1998;82:1874-1880.

10 Lau S, Chenmeister IK, Stachs A, Gerber B, Krause A, Reimer T: Pathologic nipple discharge: surgery is imperative in postmenopausal women. Ann Surg Oncol 2005;12:246-251.

11 Woods ER, Helvie MA, Ikeda DM, Mandell SH Chapel KL, Adler DD: Solitary breast papilloma: comparison of mammographic, galactographic, and pathologic findings. Am J Roentgenol 1992;159: 487-491. 
12 Dinkel HP, Trusen A, Gassel AM. Rominger M, Lourens S, Müller T, Tschammler A: Predictive value of galactographic patterns for benign and malignant neoplasms of the breast in patients with nipple discharge. Br J Radiol 2000;73:706-714.

13 Dinkel HP, Gassel AM, Müller T, Lourens S, Rominger M, Tschammler A: Galactography and exfoliative cytology in women with abnormal nipple discharge. Obstet Gynecol 2001;97:625-629.

14 Peters J, Thalhammer A, Jacobi V, Vogl TJ: Galactography: an important and highly effective procedure. Eur Radiol 2003;13:1744-1747.

15 Dawes LG, Bowen C, Venta LA, Morrow M Ductography for nipple discharge: no replacement for ductal excision. Surgery 1998;124:685-691.

-16 King TA, Carter KM, Bolton JS, Fuhrman GM A simple approach to nipple discharge. Am Surg 2000;66:960-965.
17 Gray RJ, Pockaj BA, Karstaedt PJ: Navigating murky waters: a modern treatment algorithm for nipple discharge. Am J Surg 2007;194:850-855

18 Kim SH, Cha ES, Kim HS, Kang BJ, Choi JJ, Jung JH: Galactography acquired with digital mammography in patients with nipple discharge: a retrospective analysis. Arch Gynecol Obstet 2009;280:217-222.

19 Hou MF, Huang TJ, Liu GC: The diagnostic value of galactography in patients with nipple discharge. Clin Imaging 2001;25:75-81.

20 Berná-Serna JD, Torres-Alés C, Berná-Mestre JD, Sola-Pérez J: Galactography: an application of the Galactogram Imaging Classification System (GICS). Acta Radiol 2010;51:128-136.

21 American College of Radiology (ACR): ACR BIRADS, mammography; in ACR Breast Imaging Reporting and Data System: Breast Imaging Atlas, 4th ed. Reston, VA, American College of Radiology, 2003.

22 Schwab SA, Uder M, Schulz-Wendland R, Bautz WA, Janka R, Wenkel E: Direct MR galactography: feasibility study. Radiology 2008;249:5461.

23 Rissanen T, Reinikainen H, Apaja-Srkkinen M Breast sonography in localizing the cause of nipple discharge: comparison with galactography in $52 \mathrm{pa}-$ tients. J Ultrasound Med 2007;26:1031-1039.

24 Kapenhas-Valdes E, Feldman SM, Cohen JM, Boolbol SK: Mammary ductoscopy for evaluation of nipple discharge. Ann Surg Oncol 2008;15:27202727.

25 Uchida K, Fukushima H, Toriumi Y, Kawase K, Tabei I, Yamashita A, Nogi H: Mammary ductoscopy: current issues and perspectives. Breast Cancer 2009;16:93-96. 